\title{
O DESCARTE INCORRETO DE FÁRMACOS E SEUS IMPACTOS NO MEIO
}

\section{AMBIENTE E NA SAÚDE PÚBLICA}

\author{
Natália Bitu Pinto, Universidade Federal de Campina Grande (UFCG), \\ natalia.bitu@ufcg.edu.br \\ Jacqueline Pires Gonçalves Lustosa, Universidade Federal de Campina Grande (UFCG), \\ jacque.gaya@gmail.com \\ Maria do Carmo de Alustau Fernandes, Universidade Federal de Campina Grande (UFCG), \\ maria.alustau@ufcg.edu.br
}

\section{RESUMO}

Os problemas gerados pela destinação inadequada dos resíduos sólidos são vários, principalmente, aqueles provenientes de fontes especiais como os vinculados aos serviços de saúde. O uso irracional de medicamentos no Brasil é considerado um dos maiores do mundo. Eles são produtos químicos que não podem ser jogados em lixo comum, embora este seja o principal destino de descarte dessas substâncias. Trata-se de um erro, uma vez que o sistema de esgoto brasileiro não está preparado para fazer o tratamento adequado de resíduos tóxicos provenientes de medicamentos que são atirados na pia ou no vaso sanitário. Desta forma, a população precisa e deve ser conscientizada acerca dos perigos produzidos pelo descarte de sobras de medicamentos decorrentes de aquisição desnecessária ou do não cumprimento do esquema terapêutico proposto pelo médico, bem como diminuir a automedicação.

Palavras-chave: Medicamentos. Meio ambiente. Descarte. Saúde pública.

\begin{abstract}
The problems generated by the inadequate disposal of solid waste are several, mainly those from special sources such as those linked to health services. The drugs irrational use in Brazil is considered one of the largest in the world. They are chemicals that can not be thrown into ordinary waste, although this is the primary disposal destination for these substances. This is a mistake, since the Brazilian sewage system is not prepared to properly treat toxic waste from medicines that are dumped in the sink or toilet bowl. In this way, the population needs and should be made aware of the dangers caused by the disposal of leftover medicines resulting from unnecessary acquisition or failure to comply with the therapeutic scheme proposed by the physician, as well as to reduce self-medication.
\end{abstract}

Keywords: Medicines. Environment. Discard. Public health. 


\section{INTRODUÇÃO}

Um dos grandes desafios da atualidade é a geração e a disposição final de resíduos sólidos na superfície do planeta, assim como a sua complexidade e periculosidade. Gerados pelas atividades humanas domésticas, comerciais, rurais, industriais e médico-hospitalares, esses resíduos, quando descartados inadequadamente, causam impactos negativos nas características físicas, químicas e biológicas do meio natural, sobretudo, da água e do solo que põem em risco a saúde e a sobrevivência dos seres humanos (MUCELIN; BELLINI, 2008).

A utilização de medicamentos é uma questão social presente na maioria das residências. Nesse contexto, há uma preocupação alarmante em relação aos problemas oriundos do uso dessas substâncias, tais como: automedicação, intoxicação, desperdício e descarte incorreto (IOB; CAMILO; PETRY, 2013). O descarte de medicamentos vencidos, contaminados, interditados ou não utilizados, embora não haja uma atenção especial para esse tipo de lixo, podem causar contaminação do solo e da água se dispostos em locais inadequados, como lixões e terrenos abandonados.

Dentro desse contexto, o principal objetivo do presente artigo é analisar o descarte incorreto de fármacos e os impactos no meio ambiente e na saúde pública.

\section{METODOLOGIA}

Foi utilizada uma pesquisa bibliográfica utilizando fontes primárias e secundárias. Foram pesquisados artigos científicos nas bases de dados Lilacs, Bireme, Pubmed, Scielo, e outras a respeito da temática abordada no trabalho. Foram selecionados artigos em português e inglês.

Esta análise foi feita por meio de dados secundários levantados através de sites e artigos publicados em periódicos. A parte conceitual e teórica foi obtida também por meio da pesquisa bibliográfica em torno do tema exposto.

\section{DESCRIÇÕES, RESULTADOS, INTERPRETAÇÕES}


O consumo cotidiano de produtos industrializados é responsável pela contínua produção de lixo. A produção de lixo nas cidades é de tal intensidade que não é possível conceber uma cidade sem considerar a problemática gerada pelos resíduos sólidos, desde a etapa da geração até a disposição final. Nas cidades brasileiras, geralmente esses resíduos são destinados a céu aberto (IBGE, 2006 apud MUCELIN; BELLINI, 2008).

O termo "resíduo sólido", como o entendemos no Brasil, significa lixo, refugo e outras descargas de materiais sólidos, incluindo resíduos sólidos de materiais provenientes de operações industriais, comerciais e agrícolas e de atividades da comunidade, mas não inclui materiais sólidos ou dissolvidos nos esgotos domésticos ou outro significativos poluentes existentes nos recursos hídricos, tais como lama, resíduos dissolvidos ou suspensos na água, encontrados nos efluentes industriais, e materiais dissolvidos nas correntes de irrigação ou outros poluentes comuns da água." (MACHADO, 2006).

Os problemas gerados pela destinação inadequada dos resíduos sólidos são vários, principalmente, aqueles provenientes de fontes especiais como os vinculados aos serviços de saúde. Profissionais de diversas áreas do conhecimento, tais como Ecólogos, Biólogos, Geógrafos, Ambientalistas e Profissionais da Saúde têm se preocupado com as consequências resultantes da relação entre tipos e fontes de resíduos com os desequilíbrios ambientais e os riscos para saúde humana.

O Brasil é um dos países que mais consomem medicamentos atualmente. Este uso, na maioria da vezes, é feito de forma indiscriminada e sem prescrição médica. Uma das consequências dessa prática é o descarte incorreto, principalmente, no lixo comum sendo o destino final destas substâncias (CRUZ et al., 2016).

O medicamento é um bem essencial à saúde, uma importante ferramenta terapêutica nas mãos dos médicos, além de ser responsável por parte significativa da melhoria da qualidade e expectativa de vida da população. Entretanto, uso irracional dessas substâncias e as consequências desta prática elevam os gastos na área da saúde, o que torna o tema de grande relevância para os que trabalham com saúde pública (ARRAIS et al., 2005).

A automedicação é uma forma comum de autoatenção à saúde, que consiste no consumo de um produto com o objetivo de tratar ou aliviar sintomas ou doenças percebidos ou mesmo de promover a saúde, independentemente da prescrição profissional. $\mathrm{O}$ ato de se automedicar é um fenômeno potencialmente prejudicial à saúde individual e coletiva, pois nenhum medicamento é inócuo à saúde. 
O uso inadequado de substâncias e até mesmo de drogas consideradas simples pela população, como os medicamentos de venda livre, como os analgésicos, podem acarretar diversas consequências como: reações de hipersensibilidade, resistência bacteriana, estímulo para a produção de anticorpos desnecessária, dependência do medicamento sem necessidade, hemorragias digestivas, dentre outros. A intoxicação por medicamentos é responsável por $29 \%$ das mortes no Brasil e, na maioria dos casos, é consequência da automedicação. Além disso, o alívio momentâneo dos sintomas pode mascarar a doença de base, podendo agravá-la (ARRAIS et al., 2005).

Automedicação é um procedimento caracterizado fundamentalmente pela iniciativa de um doente, ou de seu responsável, em obter ou produzir e utilizar um produto que acredita que lhe trata benefícios no tratamento de doenças ou alívio de sintomas (PAULO; ZANINI, p. 69). De acordo com os autores há vários fatores que influenciam esta prática. A automedicação feita de forma correta pode trazer benefícios para a saúde. Segundo a OMS (1998), a automedicação responsável é entendida como parte das ações de autocuidado. A OMS (1998, p. 2-3) define autocuidado como: automedicação é a seleção e o uso de medicamentos por pessoas para tratar doenças autodiagnosticadas ou sintomas e deve ser entendida como um dos elementos do autocuidado. .

A automedicação responsável requer que os medicamentos utilizados sejam de segurança, qualidade e eficácia comprovadas; e que sejam aqueles indicados para "condições" autorreconhecíveis e para algumas condições crônicas ou recorrentes (seguindo um diagnóstico médico inicial). Em todos os casos, estes medicamentos devem ser especificamente designados para o propósito, e requerem dose e forma farmacêutica apropriada.

Apesar da automedicação ser uma prática comum e possibilitar agravos e mascaramento de doenças, interações medicamentosas e intoxicações, poucas pesquisas sobre o tema foram realizadas no país. Haak (1989, p. 143-150) realizou estudo sobre padrões de prescrição em dois povoados da Bahia, incluindo 62 famílias selecionadas ao acaso. $\mathrm{O}$ autor constatou que praticamente todos os medicamentos utilizados no contexto da automedicação pertencem aos grupos dos antibióticos, analgésicos, vitaminas e anticoncepcionais. Quanto à racionalidade biomédica, considera-se racional apenas uma minoria e que a população apresenta um nível de expectativa exagerado em relação aos medicamentos.

Segundo Weiderpass, Béria, Barros et.al (1998, p. 337): o consumo de medicamentos é um indicador indireto de qualidade dos serviços de saúde, assim como da propaganda 
dirigida a médicos e populações. Seu estudo pode ser utilizado também para identificar a necessidade de intervenções específicas com: esclarecimento à população quanto ao seu uso adequado; formação e educação continuada de profissionais da saúde para a prescrição racional; identificação de populações em risco de consumo crônico de medicamentos inadequados. Além disso, pode subsidiar a elaboração de políticas públicas para conter a venda e o uso de medicamentos desnecessários.

No entanto, a utilização inadequada de medicamentos pode tornar difícil a detecção de doenças, pois as complicações são verificadas em longo prazo, fazendo com que não se percebam efeitos indesejáveis que a automedicação pode acarretar como, agravos e mascaramento de doenças, interação medicamentosa e intoxicações (PAULO; ZANINI apud ARRAIS, COELHO, BATISTA, CARVALHO, RIGHI, ARNAU 1997, p. 71-77)

Outro problema relacionado a medicamento é o destino daqueles que sobram de tratamentos finalizados e dos que são comprados em quantidades desnecessárias são guardados para serem utilizados novamente. Assim, a falta de tempo para ir ao médico ou a carência de atendimento de consultas gratuitas, ou o acreditar que não é necessário procurar um médico faz com que se utilizem prescrições anteriores (GASPARINI, 2010). O mesmo autor afirma que a população é a peça chave na solução dos problemas causados pelos medicamentos quando inadequadamente descartados no ambiente. Porém, para que esse papel seja exercido de forma consciente e absoluta, é necessária a educação juntamente com a consciência ambiental e o acesso à informação ambientalmente correta, para que assim, com essa informação, possa exercer, de forma plena, a defesa da sustentabilidade.

Ainda, conforme Gasparini (2010), “o descarte inadequado é feito pela maioria das pessoas por falta de informação e divulgação sobre os danos causados pelos medicamentos ao meio ambiente e por carência de postos de coleta". (2010, p.42). Para tal, a falta de informação faz com que as pessoas descartem esses medicamentos no lixo comum ou em vasos sanitários, mas conforme Sottoriva (2009), o sistema de esgoto brasileiro não está preparado para fazer o tratamento adequado de resíduos tóxicos provenientes de medicamentos que são atirados na pia ou no vaso sanitário.

Existem algumas tendências básicas quanto às tentativas de minimização desses resíduos: reciclagem, incineração completa e aterros sanitários. No entanto, o descarte inadequado de medicamentos vencidos pode causar sérias intoxicações no ser humano e também no meio ambiente. "Os remédios têm componentes resistentes que se não forem 
tratados acabam voltando para nossa casa e a gente pode até consumir água com restos de remédios. Eles são produtos químicos e não podem ser jogados no lixo comum". (NASCIMENTO, 2008, p. 01).

Até a promulgação da Política Nacional de Resíduos Sólidos (Lei n. ${ }^{\circ}$ 12.305, de 2 de agosto de 2010), esses resíduos sólidos eram negligenciados pelo poder público, legisladores e administradores, o mesmo fato ocorria com o descarte de medicamentos, que muitas vezes é realizado sem o atendimento dos critérios ambientais (BALBINO; BALBINO, 2012).

Para o descarte correto de medicamentos, devem ser observados os critérios específicos diante das propriedades características de cada um deles, no intuito de evitar danos ao meio ambiente, águas, solos e animais. Esses critérios estão explícitos na Norma Técnica da ABNT nº 10.004/2004, na Resolução Anvisa n 306/2004 e na Resolução Conama

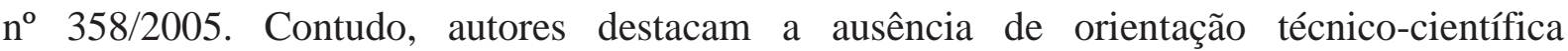
consolidada nos aparatos legais existentes no Brasil, caracterizada por uma escassa disponibilidade de dados e informações com rigor científico no que tange às possibilidades de manejo e tratamento dos resíduos (ALENCAR et al., 2014; FALQUET; KLIGERMAN; ASSUMPÇÃO, 2010).

As discussões com o Estado por intermédio dos Conselhos de Saúde são de extrema importância para a implementação de um sistema organizacional viá- vel, ambientalmente correto e com intuito de dirimir o descarte de medicamentos, atenuando os estoques de medicamentos ociosos presentes nas residências. Para ter êxito, não basta somente colocar locais de coleta, é preciso realizar educação em saúde, instruir a população para que todos adquiram conhecimento suficiente para utilizar corretamente os medicamentos, visando sempre o seu uso racional (IOB; CAMILLO; PETRY, 2013).

\section{CONSIDERAÇÕES FINAIS}

Pode-se observar a partir da literatura que existem algumas tendências básicas quanto às tentativas de minimização dos efeitos resíduos sólidos sobre o meio ambiente: reciclagem, incineração completa e aterros sanitários. No entanto, apesar dessas alternativas, a disposição inadequada de medicamentos é comum nos lixos urbanos e rurais, não sendo motivo de preocupação por parte da população quanto às alterações significativas da qualidade da água e do solo e de suas consequências sob a saúde humana. Os medicamentos podem possuir 
substâncias resistentes que contaminam a água, a qual pode ser consumia pela população e desencadear vários tipos de enfermidades. Portanto, a população precisa e deve ser conscientizada acerca dos perigos produzidos pelo descarte de sobras de medicamentos decorrentes de aquisição desnecessária ou do não cumprimento do esquema terapêutico proposto pelo médico, bem como diminuir a automedicação.

\section{REFERENCIAS}

ALENCAR, T.O.S.; MACHADO, C.S.R.; COSTA, S.C.C.; ALENCAR, B.R. Descarte de medicamentos: uma análise da prática no Programa de Saúde da Família. Ciência \& Saúde Coletiva, v. 19, n. 7, p. 2157-2166, 2014.

ARRAIS, P.S.D.; COELHO, H.L.L.; BATISTA, M.C.D.S; CARVALHO, M.L.; RIGHI, R.E.; ARNAU, J.M.; Perfil da Automedicação no Brasil. Revista de Saúde Pública. v 31; n 1; p. 71-77; fev. 1997.

BALBINO, M.L.C.; BALBINO, E.C. O Descarte de Medicamentos no Brasil: um olhar socioeconômico e ambiental do lixo farmacêutico. Revista Brasileira de Estudos Jurídicos, v. 7, n. 1, 2012.

CRUZ, R.M.; TEIXEIRA, J.L.P.; SOUZA, M.M.S.; SILVA, R.F.; GOMIDES, J.N. Investigação dos medicamentos comercializados nas drogarias e a conduta quanto a política de descarte. Anais do Congresso de Ensino, Pesquisa e Extensão da UEG, v. 3, 2016.

FALQUETO E.; KLIGERMAN, D.C.; ASSUMPÇÃO R.F. Como realizar o correto descarte de resíduos de medicamentos? Ciências \& Saúde Coletiva, v. 15(Supl. 2), p. 3283-3293, 2010.

GASPARINI, J.C.; GASPARINI, A. R.; FRIGIERI, M.C. Estudo do descarte de medicamentos e consciência ambiental no município de Catanduva-SP. Disponível em:. Acesso em 13 de outubro de 2016.

HAAK, H. Padrões de consumo de medicamentos em dois povoados da Bahia (Brasil). Revista de Saúde Pública. v. 23; n. 2; p. 143-151; 1989.

HOSPITAL UNIVERSITÁRIO DO NORTE DO PARANÁ (HURNP). CENTRO DE CONTROLE DE INTOXICAÇÕES (CCI). Dados sobre intoxicações por medicamentos. Londrina, 2000. Não publicado.

IOB, G.A.; CAMILLO, E.G.S.; PETRY, R. Análise da forma de descarte de medicamentos por usuários de uma Unidade de Saúde no município de Porto Alegre/RS. Rev. Inf. Ciênc. Farm., v. 25, n. 3, p. 118-124, 2013. 
MACHADO, P.A.L. Direito ambiental brasileiro. 14. ed. rev. atual. ampl. São Paulo: Malheiros, 2006.

MOSEGUI, B. G. et al. Avaliação da qualidade do uso de medicamentos em idosos. Revista de Saúde Pública. v.33; n.5; p.437-444; out.1999.

MUCELIN, C.A.; BELLINI, M. Lixo e impactos ambientais perceptíveis no ecossistema urbano: Sociedade \& Natureza. Uberlândia. Vol. 20, No. 1, p. 111 - 124, 2008.

MUZA, Gilson M.; BELTIOL, Helloisa; MUCILLO, Gerson; BARBURI, Marco A. Consumo de Substâncias Psicoativas por adolescentes escolares de Ribeirão Preto-SP (Brasil): Prevalência do consumo por sexo, idade e tipo de substância. Revista de Saúde Pública. v 31; n 1; p. 21-29; fev. 1997.

NASCIMENTO, C.E. Descarte de Remédios: uma questão muito grave. Disponível em:. Acesso em 15 de outubro de 2011

NASCIMENTO, Carlos Eduardo. Descarte de Remédios: uma questão muito grave. Disponível em:. Acesso em 15 de outubro de 2011

PAULO, L. G.; ZANINI, A.C. Automedicação no Brasil. Revista Ass Méd Brasil, São Paulo, v.34, n.2, p.69-75, mar/abr.1988.

PEPE, V. L. E.; CASTRO, C. G. S. O. Interação entre prescritores, dispensadores e pacientes: informação compartilhada como possível benefício terapêutico. Caderno Saúde Pública. v.16; n.3; p.815-822; jul/set.2000.

SOTORIVA, P. Descarte Incorreto de Medicamentos Ameaça o meio Ambiente. Disponível em: < http://www.medicsupply.com.br/pacientes/blog/descarte-incorreto-demedicamentosameaca-meio-ambiente/>. Acesso em 16 de outubro de 2016

WEIDERPASS, E.; BERIA, J.; BARROS, F. C.; VICTORIA, C. G.; TOMASI, E.;HALPERN, R. Epidemiologia do consumo de medicamentos no primeiro trimestre de vida em centro urbano do Sul do Brasil. Revista de Saúde Pública. v 32; n 4; p.335-444; ago. 1998.

WHO. The role of the pharmacist in self-medication and self-care. Genebra: WHO; 1998. 15p. [WHO/DAP/09.13] 